\title{
Holistic review on geosolar hybrid desalination system for sustainable development
}

\author{
Dhruvin Shah ${ }^{1} \cdot$ Meet Panchal ${ }^{1} \cdot$ Aditya Sanghvi $^{1} \cdot$ Hitendrasinh Chavda $^{1} \cdot$ Manan Shah $^{2}$
}

Received: 11 November 2019 / Accepted: 20 May 2020 / Published online: 3 June 2020

(c) The Author(s) 2020

\begin{abstract}
With the increasing scarcity of water and unavailability of portable drinking water at many places, in this paper, we present a feasible solution to this problem. The only solution in sight right now is to carry out the desalination of the huge saline water bodies. The conventional methods to do so have resulted in a failure as with the consumption of fossil fuel to run them, which in turn results in global warming. This draws us more towards the usage of renewable energy and its importance in order to obtain portable water from the saline and brackish water. In this study, we present to you a novel hybrid method that uses the geothermal energy and sun energy to produce fresh drinkable desalinated water from the seawater. This proposed system does not require fossil fuel to run, and hence, along with keeping the environment pure, it is a solution to the burning problem of water crisis throughout the world. With the help of engineering and technological skills, we can draft a better future for humanity.
\end{abstract}

Keywords Geothermal $\cdot$ Solar $\cdot$ Hybrid $\cdot$ Renewable energy $\cdot$ Desalination $\cdot$ Sustainable development

\section{Introduction}

Life on earth is the manifestation of energy. The origin of fire, heat and light is energy. It is required to grow food grains that enable humans and animals to survive. The fossil fuels were exploited as surface deposits as oil, asphalt, coal from surface seepage and natural gas obtained from underground reservoirs. In the last 50 years, the global energy demand has tripled due to the number of developing countries and innovation in technology has increased and it is estimated this demand goes triple again in the next 30 years. For meeting this demand, non-renewable and renewable energy can be used, but using non-renewable energy like fossil fuels will produce an adverse effect on the environment (Shah et al. 2018a, b, c).

Freshwater is an essential thing for a human to survive on this earth. Our planet has a huge amount of water reservoirs,

Manan Shah

manan.shah@spt.pdpu.ac.in

1 Department of Mechanical Engineering, Indus University, Ahmedabad, Gujarat, India

2 Department of Chemical Engineering, School of Technology, Pandit Deendayal Petroleum University, Gandhinagar, Gujarat, India but from this $97 \%$ is saltwater and only $3 \%$ is suitable for human use. In today's era, due to the increasing pace of industrial growth and the increasing human population, the demand for fresh water has also increased drastically (Abutayeh et al. 2014). Source of freshwater is mostly underground water, rivers, lakes, but due to industrialization, these sources get polluted which is the main reason for the shortage of freshwater. Saltwater can be transformed into drinking water by using a process known as "desalination". This process of water purification uses plenty of amount of energy. Using non-renewable energy sources for desalination of water will be costlier, and it will harm the environment also adding that non-renewable energy source is limited. It has been calculated that for producing 22 million cubic metres of freshwater per day it consumes 203 million tons of oil per year, so the use of renewable energy like solar energy, geothermal energy for desalination of water should be preferred because they are inexhaustible and available free of cost, and also they are environment-friendly (Shah et al. 2019a, b, c, d).

There are basically two methods for the desalination of water. Thermal and membrane desalination methods primarily energy requirement are heat and electricity. Both of this energy can be produced using non-renewable and renewable sources. Fossil fuels are non-renewable sources by which 
we can produce heat and electricity for driving desalination plants also from solar, wind, geothermal, nuclear which are renewable sources we can produce heat and electricity. But for obtaining heat and electricity from fossil fuels their combustion takes place due to which harmful gases like $\mathrm{CO}_{2}, \mathrm{NO}_{2}, \mathrm{CO}, \mathrm{SO}_{2}$, etc., are released which have a hazardous effect on humans and the environment of the earth and also fossil fuels are available in limited quantity on earth. In contrast to fossil fuel renewable sources produce heat and electricity without any adverse effect on human health and on environment; also renewable sources are available free of cost; only the initial cost of capturing devices is required; then, it is lifetime free. Today the world has awakened from the adverse effect of non-renewable sources, so it is turning towards the use of renewable sources for running their desalination plants. Mostly heat energy from earth and sun is used as sustainable energy for running desalination plants in the world (Kabeel et al. 2013).

Solar desalination is a process by which we can convert saline seawater into freshwater by using solar energy. Heat energy from solar can be utilized directly as thermal or first it is transformed into electrical energy which in turn can help us to drive reverse osmosis unit. Solar stills, solar ponds are devices working on thermal energy from solar energy. Using photovoltaic conversion, solar thermal power plants, electrical energy can be produced from sun energy so the desalination process can be done (Goosen et al. 2011). The rainfall also occurs due to solar desalination process when seawater absorbs heat radiation of sun; it starts to evaporate; and this vapourizes water start moving up from surface and move by air; and when this vapour condenses due to dew point temperature, as a result of this freshwater is obtained in form of rain (Qiblawey and Banat 2008).

The geothermal desalination process is the process by which we can saline seawater to fresh drinking water using the heat energy available from the earth's core (Sircar et al. 2015; Shah et al. 2019a, b). The heat from geothermal energy can be utilized directly by supplying heat to salty water in multiple-effect distillation process or indirectly first producing electricity in a geothermal power plant than utilizing electricity for running reverse osmosis units. Nowadays we can directly use geothermal brine of 60-degree centigrade temperature due to recent innovation in membrane distillation technology (Goosen et al. 2011; Shah et al. 2019a, b, c, d). Geothermal energy provides constant stable energy as compared to other renewable energy sources like solar, wind. Technically, complex capture devices and costly storing devices are required in wind, solar energy. In contrast, geothermal energy does not require complex capturing device, but it requires a high exploration coat as well as a high initial investment which is a disadvantage of geothermal energy (Ghaffour et al. 2014).
This manuscript contributes towards the unanimous goal of obtaining fresh portable water. Numerous efforts have been made to carry out desalination with utmost efficiency and without harming nature. Many technologies and methods which use renewable energy sources to carry out desalination have been developed, but there is room left for a lot of improvement and we are still in a starting stage.

The reason behind writing this paper is to not only obtain portable water out of saline water but also to develop such a desalination system that can operate day and night and allround the year with harming the environment. This paper establishes a weapon which can strike the water-shortage epidemic right in its core. Therefore, the authors have decided to write this manuscript with an awakened sense of engineering and considering this as their duty and responsibility towards the world.

\section{Impact of renewable energy sources on desalination}

The use of inexhaustible energy to operate the desalination systems is the only feasible and possible option for us to counter environment hazards and to obtain fresh potable water without the use of fossil fuels. Remote regions are potentially more to be benefited from sustainable energy powered desalination systems, where the joining to the local grid is quite expensive and not a viable option, and in the regions where there is less amount of water available. With the continuous improvement of technologies-and as the world is facing scarcity of fresh water and conventional energy sources, water purification plant operating on green energy will be more preferable and demanding. There are several desalinations plants working on green energy that have been installed, but most of them are either demo project and not in full working capacity or are smaller in terms of capacity (Abdelkareem et al. 2018).

Efforts are being made from the past many years for obtaining drinkable water from saline seawater using sun energy. A handful of desalination technologies based on solar power was developed hundreds of years ago, such as solar stills. Today we have witnessed the rising demand for making conventional desalination technologies more feasible and efficient laying more focus on developing new and advanced solar powered desalination processes. As the cost of producing electricity is increasing due to an increase in the prices of fossil fuel, the demand for solar energy-driven desalination technologies has increased. The importance of solar-powered desalination systems is more in remote and rural areas that have small infrastructure and due to less availability of electricity. Small-scale solar-driven desalination systems are necessary to counter the rising water crisis 
and to cease increasing global warming (Alnaimat et al. 2018).

Another major source for running a desalination process integrated with a renewable energy source is geothermal energy. Geothermal sources can act as excellent heat sources for running the thermal desalination process. The temperatures of typical geothermal sources are in the range of $70-90{ }^{\circ} \mathrm{C}$, which are considered to be hypothetical for running low-temperature multi-effect distillation (MED) desalination. The sources providing high rate temperatures of more than $100{ }^{\circ} \mathrm{C}$ can be utilized for producing energy and also for various heat applications. The global market of geothermal energy has about operating capacity of $13.3 \mathrm{GW}$. Moreover, if every country stays determined and committed to its goal of providing geothermal energy, then the global market of geothermal energy could reach 32 GW during 2030 s. Based on current geologic knowledge and technology, we have only been able to explore around 6-7\% of the entire Earth's capacity for geothermal power. There are enormous undiscovered resources that could provide a vast load of renewable energy to grids and desalination processes across the globe (Awerbuch and van der Mast 2016). Geothermal energy proves to be one of the most promising renewable energy sources and should be utilized wisely to fight the scarcity of water, in order to obtain potable water through desalination processes and reduce the effects on climate done by non-renewable energy sources.

\section{Desalination using geothermal energy}

For domestic and industrial applications, geothermal energy has various advantages linked with it. A geothermal source can be used for removing salt from seawater due to the following benefits (Gude 2016). Geothermal energy has a good capacity factor which gives a well-balanced and continuous heat supply which in turn helps in providing firm thermal desalination and reverse osmosis process. The capacity factor is availability of sources in terms of proportion and quality. Geothermal production technology is mature, and so it is not altered by the seasonal changes and climatic fluctuations. The temperatures of normal geothermal spring are in the span of $70-90{ }^{\circ} \mathrm{C}$ in a major portion of the earth, which are considered to be used for low-temperature multi-effect distillation system. As being the only renewable source of energy with no adverse effect on environment-related to conventional sources, it is environment-friendly. Geothermal energy covers less area for producing energy as compared to all sustainable sources (Fig. 1).

\section{Desalination by direct heat of geothermal source}

\section{(1) Desalination using the heat of geothermal source}

Electricity generation from geothermal resources having a temperature of more than $150{ }^{\circ} \mathrm{C}$ and energy generation from on-shore geothermal reservoir is a mature technology, since the last four decades, that has been developed and used. Due to less economic feasibility, direct geothermal
Fig. 1 Classification of geothermal desalination

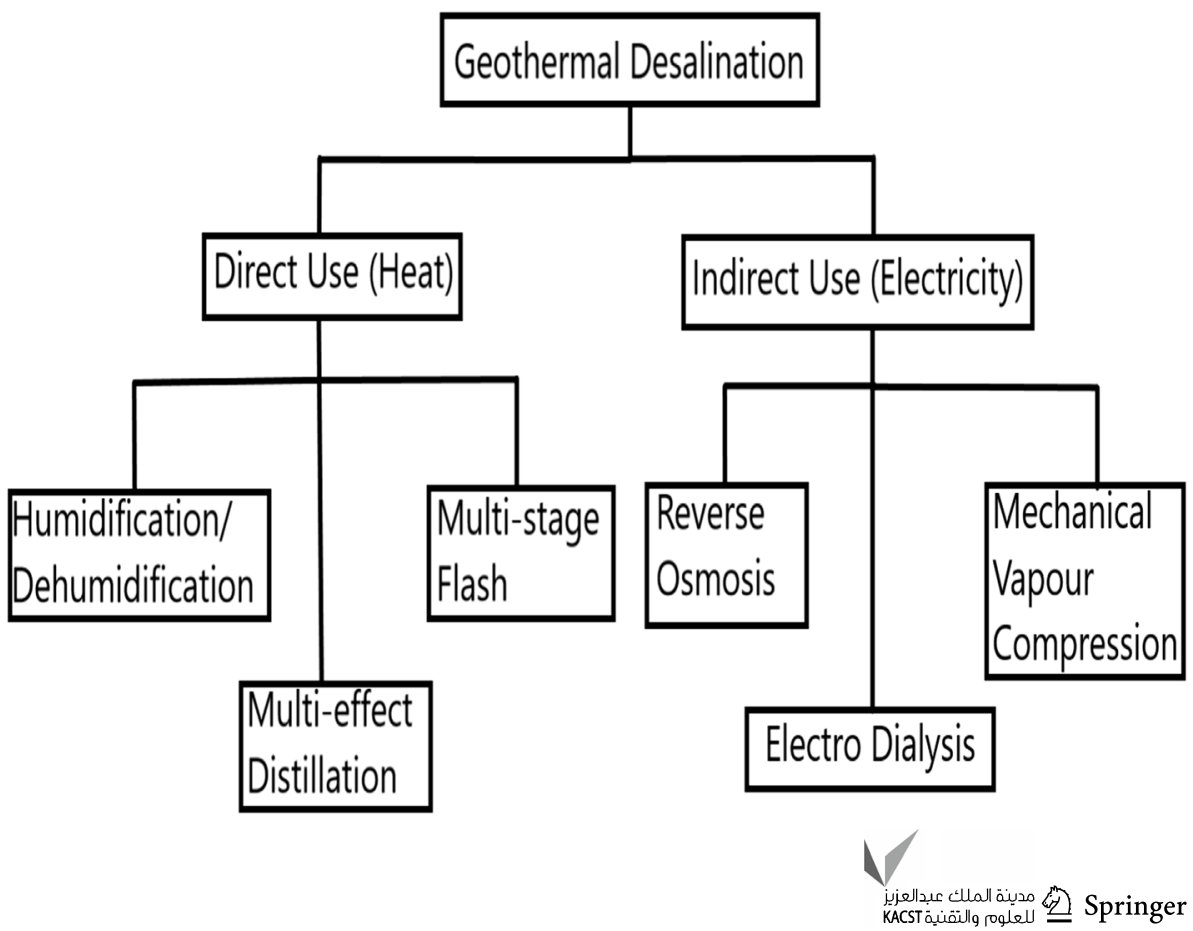


energy applications often from low-temperature resources usually $50-150{ }^{\circ} \mathrm{C}$ are not utilized if temperatures are below $120{ }^{\circ} \mathrm{C}$. However, with improving technologies, the electricity generation is improving even at fewer temperatures. These reservoirs are utilized mostly for small scale in industry, agriculture, bathing, households (Lund et al. 2011).

In contrast with other renewable sources, the main strength of the geothermal energy is that it gives continuous and clean energy. On the other hand sun and wind energy are discontinuous, so they demand technically more advance capturing devices and costly energy storing devices; in addition, they have restrictions in size scale-up large units are impossible. Moreover, if new geothermal reservoirs are targeted, high searching costs, investment risk and installation costs are drawbacks. But however, these drawbacks are countered by free of charge availability geothermal heat during working of the desalination unit in contrast to fossil fuels. Heat production from the geothermal reservoir is less costly as compared to solar, so it can be a good advantage in regions where plenty amount of geothermal reservoir is available. But mostly, economic modes choose, which alternative is the best also the hybrid solar and geothermal systems can provide a possible alternative that needs to be considered (Ghaffour et al. 2015) (Fig. 2).

\section{(2) A geothermal reservoir at temperature range $0-150{ }^{\circ} \mathrm{C}$}

Geothermal aquifers having low temperature can be obtained at less depth from the ground surface a few hundred metres, whereas geothermal resources having high temperature are mostly situated at depths level of 1000-3000 m. Due to these, the exploration of low-temperature geothermal reservoir becomes much cheaper as it demands less drilling, which is the main part of exploration and utilization charges. Lower temperatures heat also requires a low value in terms of construction and substances for the carrying heat (e.g. non-corrosive pipes). The advantages are less scaling of pipe materials and more inertness of fluid to pipes materials (Ghaffour et al. 2015).

\section{(3) Submarine geothermal resource}

The consideration for submarine geothermal reservoir has only been taken for energy production purposes. Tivey (2013) discussed the research project on their exploration in modelling chimney growth and associated fluid flow at seafloor hydrothermal vent sites. The paper says that saline water purification operated by heat of offshore geothermal reservoir has few drawbacks and moreover also has some markable advantages in comparison with on-shore geothermal reservoir. It solves the problem of discharging brines/ wastes from the plants by discharging it into the sea and in case of a small island, there is no requirement of land. This resource requires no cap rock, and recharging of the resources is done with the help of seawater. The main disadvantage is discharging geothermal fluids may lead to adverse effects on marine life, and management in the proper direction is required. If this drawback is sorted out, then submarine geothermal resources might become a potential source of geothermal energy in the future (Suárez-Arriaga et al. 2014).

\section{(4) Geothermal heat-powered desalination technologies}

The heat from geothermal can be used to operate conventionally methods such as multi-stage flash, and multipleeffect distillation or latest methods such as membrane distillation. Water heated by geothermal heat can be used for

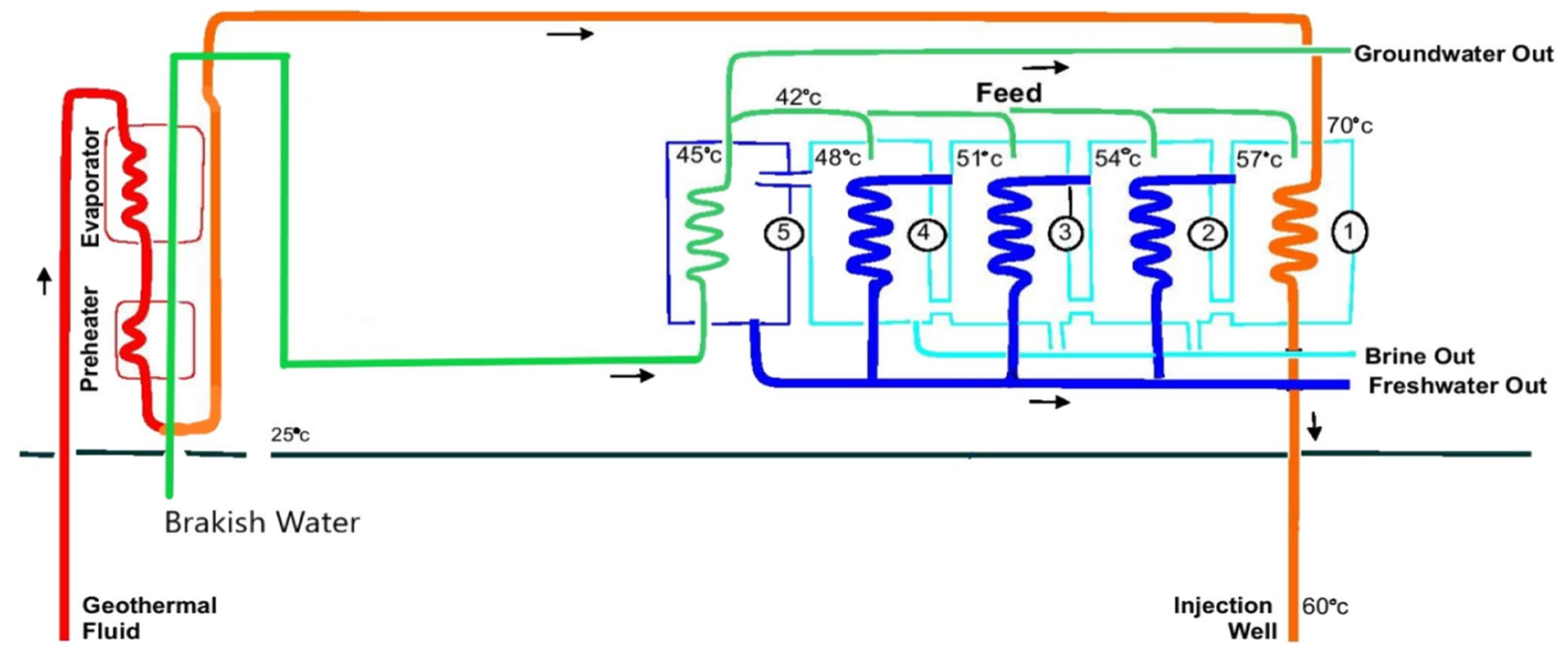

Fig. 2 Geothermal desalination generalized system 
removing salt from water operation temperature: $30-95^{\circ} \mathrm{C}$. Geothermal heat can power MSF plants operation temperature in a range of $90-110{ }^{\circ} \mathrm{C}$ by using liquid-liquid heat exchangers (Micale et al. 2009). The advantage of using the geothermal heat for operation of multiple-effect distillation is having less operating temperature $70{ }^{\circ} \mathrm{C}$ as compared to multi-stage flash. As compared to solar heat utilized for operating multiple-effect distillation and multi-stage flash plants are limited to a capacity of water production $\mathrm{b} 100 \mathrm{~m}^{3} /$ day, because of restricted dimensions of the solar pond (Ghaffour et al. 2013), while geothermal is not having such limitations to the capacity of the plants. The geothermal plants are of small scale having a capacity of $b 10 \mathrm{~m}^{3} /$ day) than the middle-scale $10-1000 \mathrm{~m}^{3} /$ day at last large-scale $\mathrm{N} 1000 \mathrm{~m}^{3} /$ day, at present the plants having capacity of million $\mathrm{m}^{3} /$ day (Ghaffour et al. 2014; Drouiche et al. 2011), for instance, 900,000 $\mathrm{m}^{3} /$ day capacity of Al-Jubal Phase II MSF plant. Geothermal fluids can be used for adsorption-based desalination which is operating in temperature between 55 and $85^{\circ} \mathrm{C}$, making it a more efficient innovative method for purification of water. MD units, which is in the designing phase so we can increase overall efficiency and lower the various costs, and some units are available as industrial units having a capacity of range $0.5-100 \mathrm{~m}^{3} /$ day (Alkhudhiri et al. 2012; Curcio and Drioli 2005). For instance, Scarab, Fraunhofer, Memsys, Memstill are more used with geothermal fluids having running temperatures in range $50-90{ }^{\circ} \mathrm{C}$. For the above-stated methods, on the basis of the condition of the site, salty water can be transformed into drinkable water or if the proportion of minerals is less, then the water of geothermal can itself be used for drinking after desalination. If geothermal water is the only available water source, the last is especially important.

\section{Important studies for the application of geothermal source for the desalination process}

Luqman et al. (2019) worked to generate hydrogen, power, fresh water, oxygen and heating altogether and established one new system based on a combination of solar and wind energy. In their system, Luqman and his teammates employed parabolic trough solar collectors and wind turbines to establish a primary source of power. In addition, to generate hydrogen with their method, they also used a proton exchange membrane (PEM) water electrolyzer. Upon various demo experiments, they concluded that the developed hybrid method showed around 50\% efficiency, while the total exergy efficiency of the system entailed to be around $34 \%$. Refrigeration based upon the principle of vapour compression was used in Luqman's system which uses employable electricity, and also for the production of hydrogen, a PEM electrolyzer was used that calls for a large input of power.
Yu and Yu (2019) in his work talked about the simultaneous generation of power and fresh portable water where there is plenty of availability of geothermal energy sources. They proposed a combination of three systems for obtaining power and fresh water, namely a steam system (SS), a single-flash system (SFS), and a trilateral flash system (TFS). Through various experiments and demonstrations, they concluded that for generating portable water, TFS is highly advantageous when compared with traditional power systems. With TFS, 2.7 times higher portable drinking water can be obtained by employing a $20 \%$ efficient turbine. Thus it was recognized that TFS can be employed when it comes to power generation and obtaining fresh water in arid regions having plenty of geothermal sources.

Chandrasekharam et al. (2019) in his review paper analysed and highlighted the water crisis that Egypt faces. They concluded that Egypt is facing the worst water crisis, and the only way for the country to prosper through that is by desalinating water from the Red Sea and the Mediterranean Sea. Obtaining portable water from these two water sources can help reach its Sustainable Development goals and counter the crisis of food and water in the country. They found out that by exploiting its geothermal energy sources, Egypt can reach a target of fulfilling $1000 \mathrm{~m}^{3} /$ year per capita water usage by 2025 . The traditional technologies used for obtaining fresh water cannot be used any longer citing global problems by $\mathrm{CO}_{2}$ emissions. Additionally, they found out that producing desalinated water through geothermal energy sources is also economically better as compared to using fossil fuels for the process.

In his citation, Gude (2019) focused on geothermal energy usage for producing portable water and explained the advantages of it along with a few setbacks. Geothermal energy is a versatile method and can be used to produce power along with portable water through various methods like multi-stage flash distillation, multi-effect distillation technologies. Also, using this power source has additional perks like lower corrosion rates, low-cost materials of construction with longer plant life, lower scaling, lower heat losses and shorter start-up periods which makes geothermal energy a priority in renewable sources.

Davies and Orfi (2014) discussed the utilization of water from geothermal sources in desalination is an almost unchartered scientific theory. There are only a few numbers of concept estimate and recognizing the use of geothermal water as a main heating source for removing salt from water is accessible. Geothermal energy sources having high temperatures are acceptable for the creation of electricity, while sources having less temperature can be used for the salt removal process from water. Hot groundwater can be used without any treatment to large distillation plant or power plant.

The initial study of desalination using geothermal was analysed and also proposed by Awerbuch et al. 1976 to 
create electricity and drinkable water from brines obtained from the ground (Awerbuch et al. 1976). The process includes a separator, turbine running by steam and multistage flash unit. The work of the separator is to separate the steam coming from the high-temperature brine extricated from the production well of geothermal should be passed through the steam turbine, while the hot brine which is not evaporated completely should be used to create drinkable water, as the raw water to the multi-stage flash unit. Early time research at the test site situated at East Mesa estimated the possibility evaporator of the vertical tube, and multi-stage flash and electrodialysis desalination processes operated using geothermal energy (Boegli et al. 1977). In distillation units, tubes were used for heat transfer, while prior checked membranes of Teflon-backed, membranes made up of Dacron and polypropylene backed in thin cell arrangement were evaluated in high-temperature electrodialysis processes. Data were gathered to analyse the coefficients of heat transfer, feed, fouling of tubes and scaling of pipes effects, cell-pair resistance, membrane fouling. To counter the side effects of silica, calcium carbonate and barium sulphate depositions, pretreatment having of poly-phosphate adding in distillation units and acidification was performed for electrodialysis. This operation has two-stage and three-stage operations at $60{ }^{\circ} \mathrm{C}$ and $72{ }^{\circ} \mathrm{C}$, while multi-stage flash and vertical tube evaporator units were analysed at both Peak and low temperatures at $135^{\circ} \mathrm{C}$ and $87^{\circ} \mathrm{C}$. The benefit of using earth heat as a source is they are ideal for thermal desalination processes because the energy obtained in output is generally available in steady conditions. Also, benefits with geothermal sources are that water from the earth can serve both as raw water and medium of heat transfer for the removal of salts.

Karytsas (1996) has described a case study of seawater desalination plants operated on low-temperature geothermal energy sources on the Milos Island in Greece. The prototype provided by him proposed the coupling of multi-effect distillation setup with an underground earth heat source having temperatures between 75 and $90{ }^{\circ} \mathrm{C}$. The research declared that the using low-temperature geothermal energy would aid us to preserve $5000 \mathrm{TOE} /$ year for a plant having productivity ranging $600-800 \mathrm{~m}^{3} /$ day useable water and thus also help in preserving the environment. In the situation of having a restricted source of geothermal, desalination processes having principle operation of thermal such as multi-stage flash, thermal vapour compression, multi-effect distillation, single-stage flash distillation highly benefited when linked to the source of geothermal by minimizing demand of energy initial heating.

Bouchekima (2003) analysed the working of solar still in which impure water geothermal sources were used as raw water in a plant located at South Algeria. In South Algeria, all the geothermal sources obtained are low energy sources having a maximum capacity of a range of $60-70{ }^{\circ} \mathrm{C}$. A new distillation process operated on solar having capillary film was invented and thoroughly analysed. A comparison was made between the theoretical study of the heat energy and mass transfer phenomenon in this distiller operated on solar with the experimental output from the working unit. The distiller having capillary film, combined with recovery, has the potential to makeup water up to $20 \mathrm{~L} / \mathrm{m}^{2}$ day; on the other hand, old design solar still has a capacity of $5 \mathrm{~L}-6 \mathrm{~L} / \mathrm{metre}^{2} /$ day surface area of the collector.

Bourouni et al. (1999a, b) demonstrated a promising aeroevaporate-condensation process for chilling also for removing salt through geothermal brackish water. The evaluation of heat energy and mass transferring phenomenon in the process was done with the aid of modelling and practical analysis with a geothermal fluid having temperatures of $60-90{ }^{\circ} \mathrm{C}$. A cost comparison was done between the desalination costs operated by geothermal for the proposed method and water desalination technique which are available. The calculated price for this method is $\$ 1.15 / \mathrm{m}^{3}$ when operated using geothermal sources; on the other hand, if heat energy is applied by the source of fossil fuel, the price was hiked up to $\$ 4.80 /$ $\mathrm{m}^{3}$, which is way more if considered in masses. While the prices for various methods are proposed as multi-stage flash costs $\$ 1.57 / \mathrm{m}^{3}$ having turbine of back-pressure steam, multistage flash having turbine of gas and boiler operated on waste heat it costs $\$ 1.44 / \mathrm{m}^{3}$, and thermal vapour compression consists of a turbine of gas and boiler running on waste heat cost $\$ 1.31 / \mathrm{m}^{3}$. Mohamed and El Minshawy, also done practical and theoretical researches on removing salt from the water with the help of dehumidification-humidification technique which is the same as Bourouni et al. (1999a, b) in Egypt (Mahmoudi et al. 2009a, b).

Mahmoudi et al. (2010) proposed a method-purifying water with greenhouses gas desalination method running on heat from earth, i.e. geothermal source. As in Algeria, this method is appropriate for dry and cold surrounding conditions in local regions. It is the same as the dehumidification and humidification of air. In this process, a heat-transferring device installed in the ground is used to preheat water coming from a geothermal source suitable for this given desalination technique which contains vapourization and cooling surfaces on combining with increasing temperature of greenhouse gas. They concluded through analysis and experiment that heat from the ground is the most suitable application for purification of inland brackish water.

Koroneos and Roumbas (2012) studied that geothermal sources have the capacity in the Greek island of Nisyros located in the south-eastern part of the Aegean Sea for removing salt from seawater and electricity creation, using separately, and the connected method was proposed. Due to its requirements of lower energy and less scaling and 
operating at less temperature a multi-effect distillation was suitable in this study. To understand the thermodynamic performance of the desalination plant, an analysis of the demand for energy by the desalination unit was also calculated. Furthermore, a life span evaluation was also done on the multi-effect distillation desalination and electricity creation-linked scheme. The environmental impacts were reported to be negligible as in the case of the plants operated by fossil fuels. Also from this method, the waste heat obtained from the plant was used for the salt removing process from water.

The presence of boron is to be a minor drawback using water from geothermal sources imposing a restriction on the usage and other uses. Additional processes for removing boron should be used in water purification plants because reproductive and developmental toxicity in animals and crops occurs due to the presence of boron in water. In Poland and Turkey, much research was done by scientists on many types of waters from the ground, and radioactive compounds such as radium, radon and tellurium are also present in that water. Several hybrid methods coupled with membranes methods and electrode ionization resin methods are developed to remove the Boron proportions up to some levels which are less than $1.0 \mathrm{mg} / \mathrm{L}$.

\section{Solar desalination}

The solar desalination process in which we are using is usually a small-scale process of natural hydrological cycle used for rain. Research and industries have proved that solar desalination is better than mechanical desalination for large capacity plant applications (Fig. 3).
Solar desalination process is of two types

(1) Direct solar desalination

(2) In-direct solar desalination

Direct solar desalination process utilizes solar energy directly for producing freshwater, but indirect solar desalination heat of solar is used to run conventional desalination methods like multi-effect evaporation, multi-stage flash, reverse osmosis, etc. (Shatat and Riffat 2014) (Fig. 4).

Solar still Solar still is a direct solar desalination process in which the collection of heat and distillation processes occurs in the same unit. Brackish water is placed inside airtight transparent having V shape construction where water converted into steam due to absorption of radiation from sun heat and then it starts cooling of steam on a sloppy surface by giving heat to the environment so as a result condensed droplet acts as a freshwater. A drawback of this process is it has a low production rate (Salem, 2013)

Humidification and dehumidification In this process, the air is used as a heating medium. The principle used in this process is mass diffusion. Dry air is used to evaporate saline water, so humidification of air occurs. After that freshwater is obtained by condensing the vapour so dehumidification of air occurs (Narayan et al. 2010).

Multi-stage flash distillation This process uses the distillation process through many chambers; here in each chamber pressure decreases gradually. The brackish water is heated under high pressure using heat from solar collectors of any type, and it is led to a first flash chamber where some amount of pressure decreases and water starts to boil rapidly result in sudden evaporation. This evaporation of part brackish water continues in every preceding stage because
Fig. 3 Classification of solar desalination systems

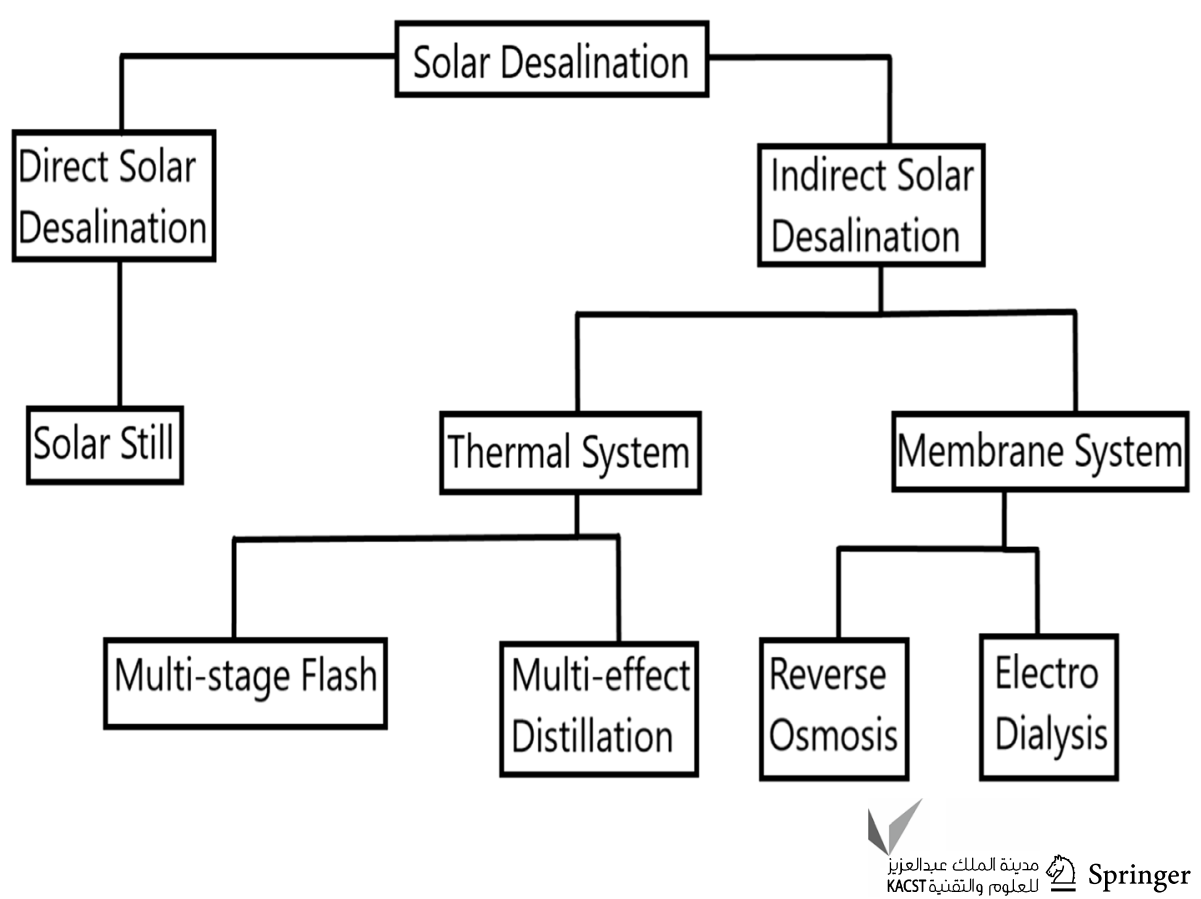




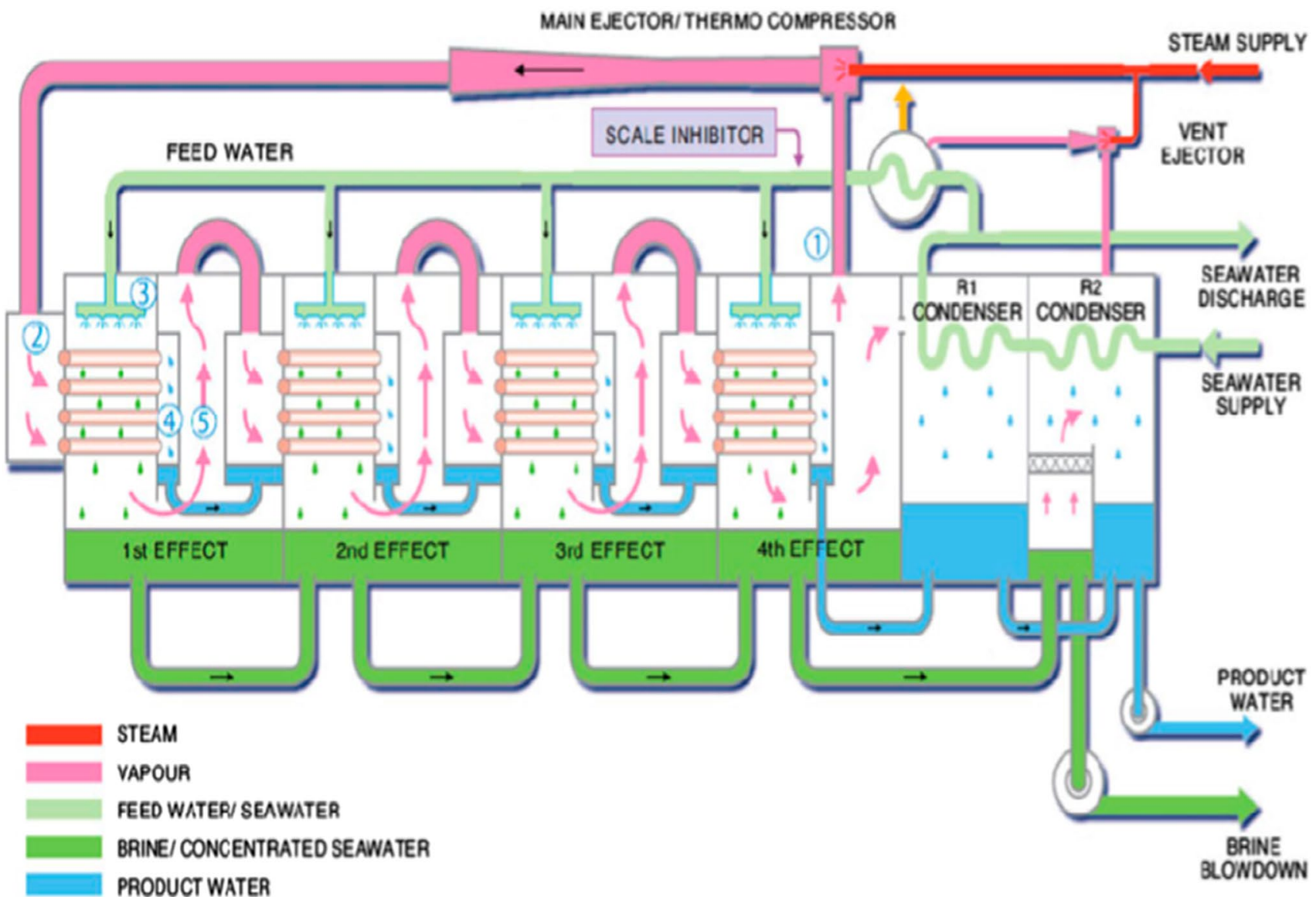

Fig. 4 Generalized solar desalination system

the pressure in every stage is reduced gradually. The vapour generated by the evaporation of water gets condensed by using a heat exchanger tube that is fitted in every chamber and that cooled water can be utilized for human purposes (Krishna 2004).

Multi-effect distillation This process occurs in a number of vessels, and the principle of evaporation and condensation is used to obtain fresh water at lower ambient pressure. In multi-effect distillation at lower pressure, a series of evaporation effects produces the water. As the pressure decreases the water is able to evaporate at low temperatures, so water vapour of the first vessel can be used as a heating source for another vessel and so on. The more the number of vessels better will be the performance ratio. Multi-effect distillation can be divided as horizontal, vertical or vertically stacked tube bundles as per the arrangement of a heat exchanger tube. The combined capacity of $3.5 \mathrm{mgd}$ of three low-temperature multi-effect distillation plant successfully operating at st. Thomas US virgin islands, where the main supply source of water is desalinated water (Ali et al. 2011).

Vapour compression desalination In combination with multi-effect distillation process vapour compression distillation process is used. The vapour produced in the first effect of multi-effect distillation is acting as a heating medium for second stage which is at a lower pressure as compared to the first stage. Using compressor vapour produced in the last stage is compressed due to which its saturation temperature is raised before it returns to. Here the device for compression is run using solar energy by photovoltaic converts. Vapour compression process is not efficient until it is not coupled with the multi-effect distillation system (El-Dessouky et al. 2000).

Freezing desalination Demonstration project is only built for this process. Because it has drawbacks like ice and water mixture which are difficult to handle, the cost and difficulties of the refrigeration system, the requirement of fresh water to wash the crystal before melting it. A standard refrigeration cycle can be used for freezing of saline water until ice is formed after that ice is washed with freshwater and melted. In Saudi Arabia, this type of solar-powered unit is constructed in last 1980 by Chicago bridge and iron, Inc., under the SOLER programme which was a joint contract between the USA and Saudi Arabia. But this unit was highly inefficient. Here solar collection point focused is used in 
heat oil; in turn, they heat salt acting as a storage medium for continuous working for heating water-producing steam which makes shaft power so refrigeration cycle can work (Qiblawey and Banat 2008).

Reverse osmosis When water containing low salt concentration is passed into a more concentrated solution through a semi-permeable membrane, it is a natural phenomenon called osmosis. Now again if pressure is applied to high salt concentration solution having pressure value more than osmotic pressure, then it will flow in reverse direction leaving the salt concentration behind and this process is known as reverse osmosis process. Salt separation is done with the help of semi-permeable membrane, and reverses osmosis system mostly depends on the properties of semi-permeable membrane material. When initial pressure is applied, then water from salt solution is passed through the membrane and collected in the brine compartment. Again if pressure more than initial pressure is applied, then water is able to pass through the membrane and goes to a freshwater compartment. The solo energy requirement is for running the pump for supplying high-pressure feedwater more than osmotic pressure 50-80 atm. The pressure is required so the proper quantity of water passes from some area of the membrane. When feed water passes via membrane major amount of dissolved solids are separated and the rest of the salts are removed at high pressure. Energy from solar can be utilized to run the pump using photovoltaic converts. The output of the reverse osmosis process is approximately $500-1500 \mathrm{~L}$ per day per square metre of membrane depending on the concentration of salt in feed water and circumstances of the membrane (Eltawil et al. 2008).

Electrodialysis $(E-D)$ In this process with the help of electrical potential difference ions in feed water is passed through a membrane which results in the reduction of salinity in feed water. DC current is normally used for generating a potential difference for the moving of ions. Feed water contains dissolved ions such as positively charged sodium and negatively charged chloride ions. The ions having characteristics of attraction towards oppositely charged electrodes. In addition to anion and cation permeable membrane some special membrane if used we can get the layer of salt deposited between the membrane. In industrial level many numbers of cation and anion membrane are coupled together having plastic spacers that allow water to pass from it. This process is efficient only when dissolved salt is less than $6000 \mathrm{ppm}$. Here the requirement of DC power can be fulfilled by using photovoltaic panels powered by solar energy (Abdelkareem et al. 2018) (Table 1).

\section{Important studies for use of solar energy for the desalination process}

(1) Lu et al. (2000) proposed a solar pond coupled with a desalination plant located at El Paso (USA). The thermal plant and RO plant both are powered by the solar pond. The standard multi-stage flash system is not able to run by connecting it with a fluctuating heat source. The solution for this problem is given by Atlantis Company developing an advance multi-stage flash system known as an AUTOFLASH which has a characteristic of coupled with a solar pond (García-Rodríguez 2002). Although the multi-effect distillation system is more beneficial as compared to a multi-stage flash system in terms of high productivity ratio and also important features of stability against the corrosion effect and effect of scaling from seawater. The proposed model works by transferring the heat energy from the heat-deposited zone of the solar pond to brine water for preheating. Furthermore, this heat is also used for reverse osmosis desalination of both seawater and brackish water after being used by the AUTOFLASH system. A new design of solar collector was invented and coupled with a multieffect humidification desalination plant. A small prototype of this model is installed at Pozo Izquierdo (Gran Canaria, Spain). Moreover, when a multi-effect distillation system coupled with a solar pond as a source of heat results are more satisfactory as compared to multi-effect flash system. In conclusion, a desalination system when connected with a solar pond is the most beneficial system in terms of operating costs.

(2) A study of sustainable polygeneration technique is presented by Calise et al. (2016) for minor remote society. $\mathrm{He}$ also proposed an eco-thermodynamics optimization and exergy-economic study. The system incorporates concentrating photo-voltaic thermal structure connected with a chiller operating on absorption principle and a group of thermal reclamation with a multi-effect distillation structure coupled with an auxiliary heater fired on biomass. In the auxiliary heater and in the solar system the maximum destruction rate of exergy takes place. However, the resulted exergy performance ratio is low for this system. The collection of solar power when done with parabolic trough collector connected with an organic rankine cycle having refrigerants like R134a and R152. The system shows the greatest efficiency, also the destruction of exergy in solar collector is $70 \%$ out of total, while organic rankine cycle evaporator has $17 \%$ exergy destruction of the total. When a double-effect and singleeffect absorption chillers equipped with a parabolic trough collector, it can be used for the solar system of heating and cooling of water in desalination plants. When a multi-effect distillation system connected with an organic rankine cycle and parabolic trough collector, then the system will be in

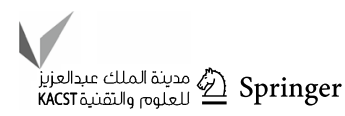




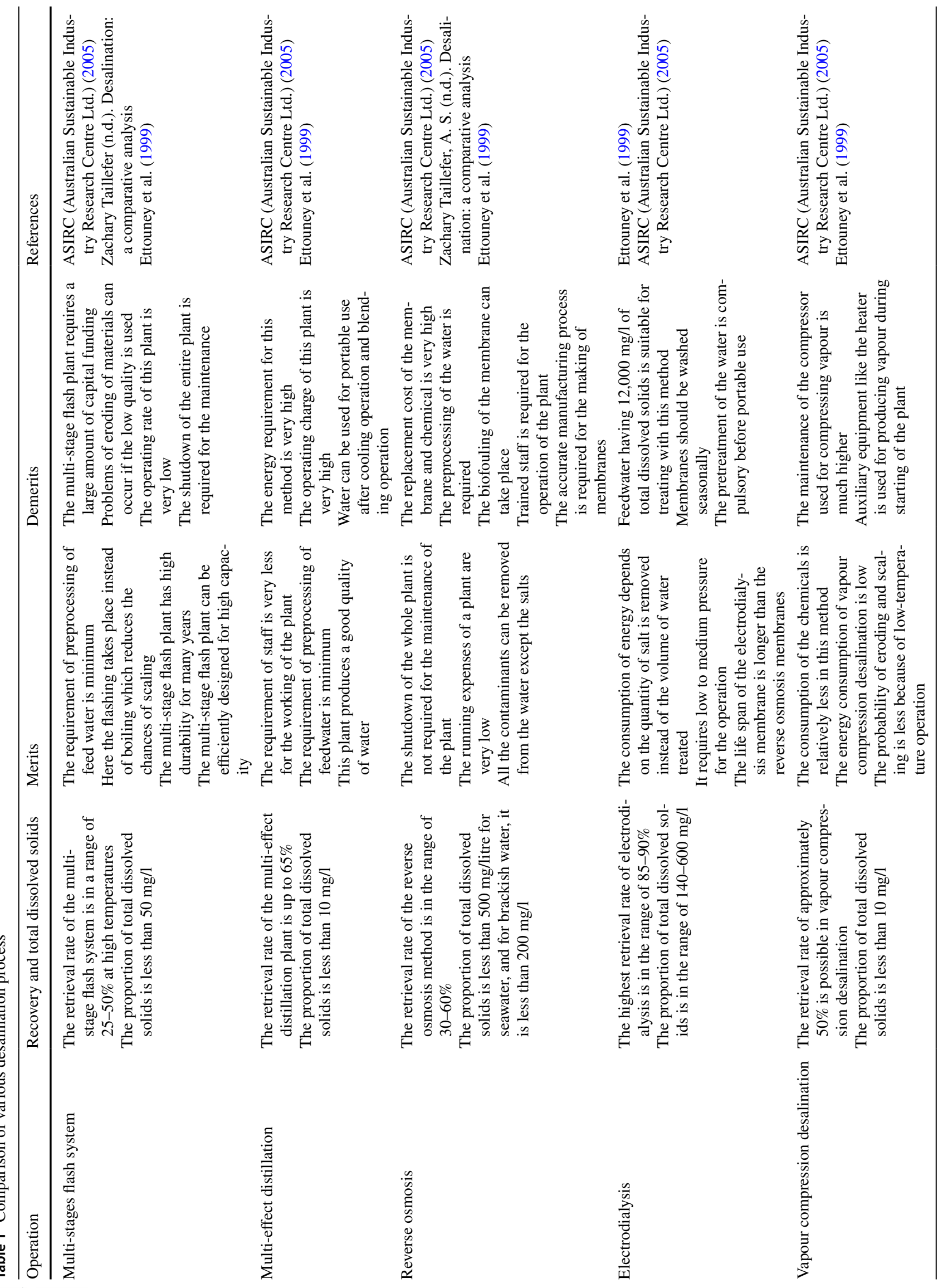


optimum condition at $700-750{ }^{\circ} \mathrm{C}$ of multi-effect distillation supply having 16-20 stages.

(3) Fernandez-Gonzalez et al. (2015) proposed the feasibility of solar photovoltaic coupled with an electrodialysis system for the desalination of water on the basis of considerations of energy and environment. He studied the electrodialysis system operated by solar and grid systems and came to the conclusion that an electrodialysis system connected with solar is more efficient than that of the grid system. The energy consumption of integrated photovoltaicelectrodialysis system obtained is $0.49-0.91 \mathrm{kWh} / \mathrm{m}^{3}$ which is much less than grid-connected system consumption. Furthermore, the negative impact on the environment is also less for the solar-operating system as compared to the grid system. The solar-coupled system is suitable for regions having a lack of electricity supply, countries not having low-cost fuel for desalination, regions having an adequate amount of sunshine, so the system can work in an optimum state. The electrodialysis energy requirement is direct current for separation of ion in saline water. So energy consumption depends on the quantity of the ions in water. This system is capable to produce drinkable water from brackish water having dissolved solids between 0.4 and $6 \mathrm{~g} / \mathrm{L}$ (Ullah and Rasul 2018). Electrodialysis reversal is a similar process like electrodialysis, but here the positive ion and negative ion get reverse so due to which electric current becomes altered. The frequency of fluctuating current is 4 times an hour. In this reversal method, the fouling and scaling of the membrane are reduced. Due to fluctuating polarity and circulation of feed water, the recovery percentage of the reversal method is more efficient as compared to simple electrodialysis.

(4) The economic and thermodynamic research is done by Baccioli et al. (2018) regarding the natural rankine cycle and multi-effect distillation plant of waste heat recovery. He compared several different layouts, namely serial cascade configuration and simple cascade configuration. From above-mentioned two layouts serial cascade configuration has more profit-making index as compared to simple cascade configuration. Furthermore, another various type of layouts compared for small capacity multi-effect distillation systems for isolated dry regions. Layouts are traditional system equipped with steam and diesel generator, the solar equipped system in which heat energy for the evaporator is given by solar collectors and diesel pump is used for pumping the fluid, lastly, the solar equipped system for supplying heat through solar collectors and pumping of fluid is done by solar photovoltaic (Liponi et al. 2020). The results showed that fossil energy outweighs solar energy in the present scenario, but in some dry isolated regions where the transportation of fuel is costlier the solar energy plays an important role in the desalination of water. The appreciation for the small-scale multi-effect distillation plant increases the practicality of the waste heat recovery system. The small capacity plant requires a reshaping in the configuration of the plant as compared to the large capacity plant, so the desalination cost can be decreased and the efficiency ratio of the plant can be increased.

Aim of Schwarzer et al. (2001) was to increase the output of the desalination system which is linked with flat plate solar collectors. So he invented a desalination tower linked with flat plate collectors different heights and condensation of water occurs in one stage underside of next stage so due where oil used as a heating medium. In tower water get evaporated at successive stages, and this heat transfer is increased and the net output of the system is also improved. We can compare the desalination tower of Schwarzer et al. by multieffect solar still. Similar kinds of results are obtained that of the tower if a solar still knows as "stacked plate still" is used which was proposed by Fernhndez and Chargoy (1990). The capacity of the production of freshwater from distillation water reaches $25 \mathrm{~L} / \mathrm{m}^{2}$ day having an energy consumption of $4.8 \mathrm{kw} / \mathrm{m}^{2}$ day of the solar radiation.

Tanaka et al. (1981) worked to increase the production of freshwater from the basin stills. He uses a porous radiationabsorbing pad through which feed water will flow and he named this still as a wick still. The advantage of wick still over basin still is wick still can be tilted, so pad gets more surface area to absorb radiation and also reduce reflection of sun rays. Also, less feed water will present in wick still because water will flow slowly through pads due to this evaporation of water will take lesser time and high-temperature steam will be obtained. At last, he proved that wick still is more productive than basin still and production rate of freshwater by wick still $20-50 \%$ more as compared to basin still because in it design of solar collectors is conventional and more amount of feed water enters at a time, so evaporation of water increased and low temperature of steam is obtained. He also claimed that if some further modifications are made in wick still design, then it can cost less than that of basin still like aluminium frame having foam insulation at bottom supported by a net of nylon ribbon, cover made of glass and water storage tank made of galvanized steel or iron.

Müller-Holst et al. (1999) designed a multi-effect humidification distillation experimental setup and want to test the performance of this setup at various operating conditions. Distillations of water under atmospheric conditions with the help of an air loop saturated with water vapour is the operating principle of a multi-effect humidification setup. Forced with fans or natural convection is used for air circulation also the combinations of evaporator-condenser cycle is known as a "Humidification cycle" because evaporator humidifies air and condenser dehumidifies it. As this setup is running on solar energy, so the capacity rate of freshwater production will get affected by seasons. He reported $6000 \mathrm{~L}$ per month as an average production rate and maximum production 
was $10,500 \mathrm{~L}$ in May month and minimum production was $1700 \mathrm{~L}$ in January month. He also suggested another design of multi-effect humidification named it "SODESA SYSTEM" having a storage tank for storing thermal at the proper pressure and a collector field. In this system feed water directly enters the collector and gets heated. The efficiency of this system is high as compared to the system with heat exchanger because here there is no loss of heat due to heat transfer through the heat exchanger. The drawback of this system is the increase in the cost of system special materials are required which can resist corrosion of seawater at $100{ }^{\circ} \mathrm{C}$ temperature.

Garmana and Muntasserb (2008) worked to find the suitable thickness for different zones in the solar pond which can be coupled with multi-effect distillation of low temperature, so maximum output from the system can be obtained. Multistage distillation system is more efficient as compared to a multi-flash system because of operating low temperatures. The steam temperature of $80-90{ }^{\circ} \mathrm{C}$ temperature is most suitable for multi-effect distillation. Both of them reported that solar pond has three zones upper convective zones of $0.3 \mathrm{~m}$ thickness, non-convective zones of $1.1 \mathrm{~m}$ thickness and at last lower convective zone of maximum thickness of $4 \mathrm{~m}$. All these lead to the continuous increasing temperature of solar pond and make more productive to low-temperature multi-effect distillation plant. Due to dust deposition on the surface of solar collectors production rate of freshwater can be drastically decreased to $40 \%$.

Ward (2003) worked to develop a water purifier operating on solar which can satisfy the need for the freshwater of poor communities. So he comes up with a plastic sheet of black colour covered with a glass window of white colour. The plastic sheet is designed as an array of an interlinked square that holds the degraded water also material having excellent properties due to which no taste, smell, the colour of the plastic sheet is transferred to the freshwater output. This water purifier is designed in such a way that it does not require any filter, electronic parts, moving parts. This purifier is capable of converting seawater containing TDS $35,000 \mathrm{ppm}$ to clean potable water having TDS of 1-2 ppm. The production rate of freshwater was $9 \mathrm{~L} / \mathrm{m}^{2}$ day at $35^{\circ} \mathrm{C}$ ambient temperature. This production rate of fresh water is sufficient for a small family that can obtain potable water from any dirty water source like the sea, borewell, brackish water, etc. The construction of the purifier consists of an aluminium frame of any shape on which a black plastic sheet is vacuum formed. So due to this final shape of sheet becomes rectangular and consists of a number of shallow and square cross-sectional trays connected by each other with weirs. In total, $100 \mathrm{ml}$ of liquid can be stored by each tray and approximately this system consists of 32 trays and some channel networks for distributing and collecting degraded and pure water. For keeping good efficiency of this system cleaning of purifiers should be done on a regular basis.

Al-Kharabsheh and Goswami (2003) proposed a system having a continuous production of water unless of batch production of a single basin still. So they designed a system in which evaporation and condensation occur in vacuum conditions. Using natural forces of gravity and atmospheric pressure vacuum is created. In this system, they have put evaporation and condenser chamber at $10 \mathrm{~m}$ height from ground level and using a solar heating system for evaporation. When hydrostatic and atmospheric pressure is balanced vacuum occurs in discharge and output pipes. Here mostly flat plate collectors are used because here low temperature is required for evaporation of water. In the evaporator when evaporation of water starts, then salinity in evaporator increases which results in a decrease in the evaporation rate of water solution of this problem to remove some amount of concentrated brine at some flow rate and simultaneously add some saline water at a rate equal to withdraw. No pumping power is required to pump saline water because of the vacuum. Ejected concentrated brine can be used to construct a solar pond by further concentrating it. Evaporation chamber is connected to the condensation chamber where water vapour condenses and freshwater is obtained which can be used for drinking purpose. Maintenance activity like periodic cleaning and flushing of system is required, so any noncondensable gas can be removed which can affect vacuum conditions. Based on the experimental and theoretical results vacuum system is more productive as compared to the simple basin solar still.

\section{Proposed model of a hybrid system for water desalination using solar and geothermal energy sources}

A humidification-dehumidification desalination method with a solar-geothermal source used as a hybrid energy source is proposed in the following Fig. 5. Evaporation of saline water inside the humidification chamber and cooling of the steam through the attached condenser in order to obtain fresh potable water is a basic principle for operating this model. Parameters such as ambient temperature, solar radiation, air temperature at solar heater inlet and outlet, water temperature in humidification container, air flow rate and relative humidity at humidification chamber inlet and outlet are to be measured. The same test rig configuration was used by Elminshawy et al. having little bit difference in air heater operated by solar and water tank for geothermal. As shown in the figure, saline seawater, brackish water is filled in a tank and passed over the solar heaters (1) as shown in the figure. To increase the turbulence, cylindrical pipes of small size having each pipe diameter as $1 \mathrm{in}$. the 
Fig. 5 Hybrid geothermal solar desalination system

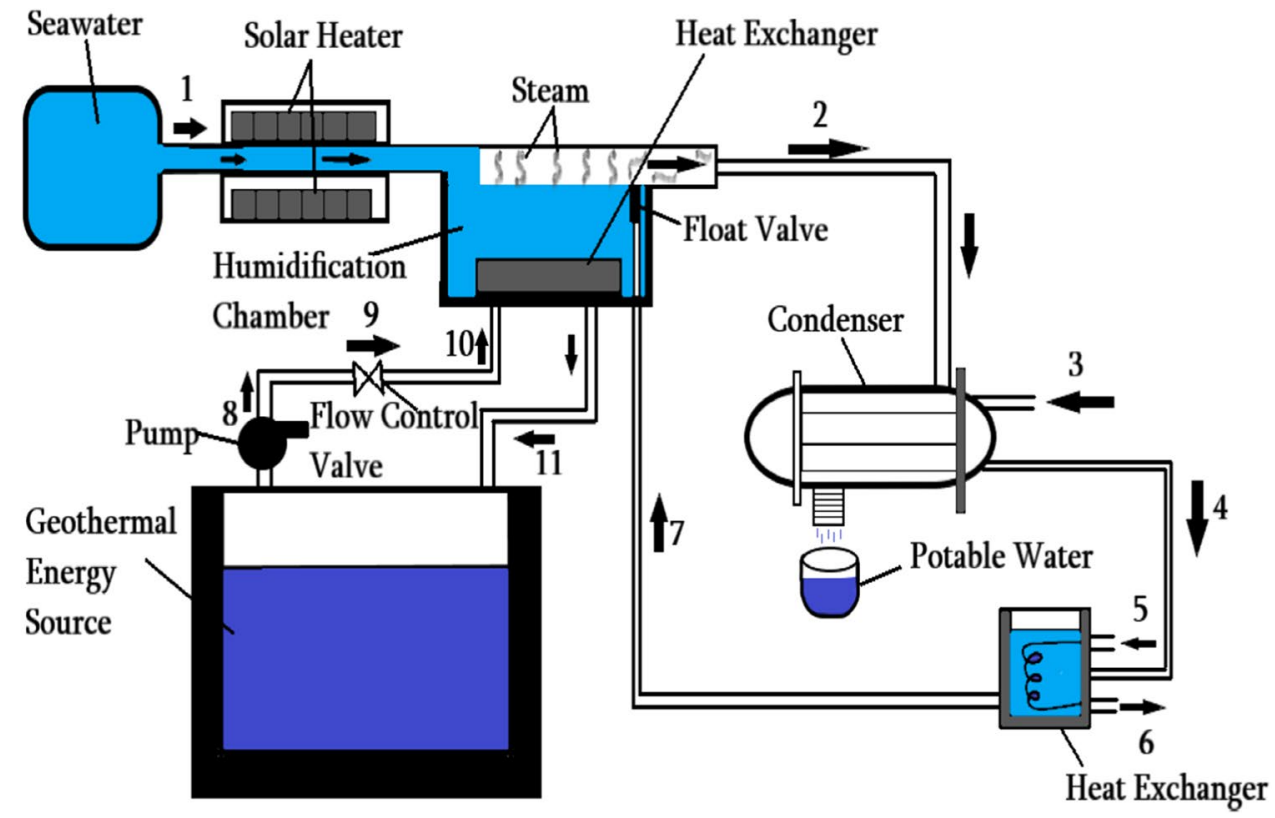

stumbled arrangement are to be used inside the solar air heater and hence the increased temperature of the air at the input of the humidity process. In order to absorb maximum radiation, a black colour coating is done on pipes also on bases. A geothermal energy source (geothermal water tank) is to transfer heat energy to the water used in the humidity process. A small water pump-bearing capacity of $0.2 \mathrm{~kW}$ is used to supply hot water from the geothermal water tank (8) to the humidification chamber (10). To have control of the water flow rate of the geothermal, the flow control valve (9) is used. This valve is located (11) at the output of the humidification chamber and entry in water tank. To transfer heat energy between the high-temperature water coming from the geothermal tank and salty water in the humidity chamber, a heat exchanger consists of a tube made up of copper material. Water from the output of the heat transfer device (11) returns to the water tank through the path mentioned. The induced water (1) when making an entry in solar heater and then its temperature is increased up to some limit before it goes to the humidification process. Due to heating effect generated by solar heaters and geothermal heat source through the heat exchanger, temperature exceeds seawater boiling temperature and it gets converted into water vapour in the humidification chamber. The left out brine then taken out from the humidification chamber through a back path (not mentioned in the figure). This water vapour then passes on to the condenser (2). Any cooling medium is used inside the condenser to cool the water vapour into pure drinking water. The cooling medium (ocean water) carries away heat of condensation (4) to the tank containing water in order to initial heating the salty water before it goes to the humidification process (7). Here water used in this proposed model comes from the treatment plant in which ocean water undergoes initial treatment against various types of dirt using different purification techniques. To measure the temperature of salty water in the humidification process, thermocouple (K-type digital) is used.

\section{Challenges and scope}

The incoming shortage of fossil fuels and day by day increasing demand for water to accomplish these more development in the field of water desalination and purification by renewable energy will be encouraged shortly. Researches are more concentrating on solar thermal, Geothermal energy sources as an alternative source of energy for operating desalination or purification plants. One of the options is to couple the renewable energy sources mostly solar or geothermal with large-scale desalination plants like multi-evaporation or multi-stage flash system so we can get potable water at some suitable cost.

However, there are some obstacles while using renewable energy for the desalination of water like society is not mature enough about the energy crisis in the world, the benefits of renewable energy and the solution of these are to educate the community. The main hindrance regarding the use of salt removing systems from water operated using solar is the productivity of the system, which is low as compared to the conventional desalination. The parameter which controls the efficiency of desalination plant using solar energy is the transfer of heat energy and masses during the vapourization and cooling process. Moreover, desalination operated on solar is not suitable for large scale industrial plant due to 
some technical and economic limitations. Also, solar radiation is not uniform in every region of countries. In addition to these geothermal sources are also not available in every part of nations, and it requires much deep drilling for utilizing it. International development association declared in 2012 that the cost of one-metre cubic of freshwater production from seawater ranges from the US \$ 0.5 to the US $\$ 1.5$ for every 1000 manglers produced. In the future, due to technological advancement costs can be reduced to the US $\$ 0.25$ for every $1000 \mathrm{~s}$ filter created so people can utilize desalination using renewable sources without any hesitation. One should remember that nature gives renewable energy free of cost, but it's our duty how efficiently we can collect that energy.

Along with the cost of obtaining portable water, geographical locations also play an important role while setting up a plant of desalination. Arid regions like Egypt serves as a huge source of Geothermal energy. The task that lies ahead is exploring the ways of extracting that energy and using it as per our need. For instance, Egypt's water crisis can be overcome by using that geothermal energy to run the desalination system and obtain fresh water from the Red Sea or the Mediterranean Sea. Using such sources of power will help us overcome many hurdles in the way of achieving sustainable development. The availability of Solar and Geothermal Energy as per our needs is the only major obstacle we face, and this can be overcome by judiciously selecting the regions for the setup of a desalination plant.

The proposed Solar-Geothermal Hybrid desalination system will not only serve as a breakthrough in the desalination technologies but will also prove to be versatile equipment that can be employed anywhere and work under any conditions.

\section{Conclusion}

This manuscript highlights the use of renewable energy sources to carry out desalination and focuses on a model which works on both geothermal solar energies to obtain fresh water. There have been numerous drawbacks and limitations while employing systems solely based on either geothermal energy or solar energy for obtaining portable water. The proposed hybrid system offers to cover up all those limitations and establishes a new approach towards the burning problem of water crisis.

Employing geothermal as well as solar energy in a desalination system provides us with a wide range of solutions. In addition, it may increase freshwater production by providing better efficiency.
This system can even operate at night or in rainy or cloudy seasons, as geothermal energy ensures us with 24-h energy supply, making the system more feasible. In sunny regions where solar energy dominates, geothermal energy can also be used for secondary electricity production.

Thus making this system least affected by weather conditions and ensures us with full capacity fresh water supply throughout the year. This system might play a major role in overcoming the water crisis and in optimizing the use of fossil fuel and make renewable energy dominating over a period of time.

The burning problem of the twenty-first century should be resolved as quickly as possible; otherwise, that day is not far when the foretells of people saying, "The reason for third world war will be WATER" will eventually come true. For the conservation of the environment and to take control of the rising global temperature, renewable energy is the only practical engineering solution.

Acknowledgements The authors are grateful to Indus University and School of Technology, Pandit Deendayal Petroleum University, for the permission to publish this research.

Author's contribution All the authors make substantial contribution in this manuscript. DS, MP, AS. HC and MS participated in drafting the manuscript. DS, MP and AS wrote the main manuscript, and all the authors discussed the results and implication of the manuscript at every stage.

Availability of data and material All relevant data and material are presented in the main paper.

\section{Compliance with ethical standards}

Conflict of interest The authors declare that they have no competing interests.

Open Access This article is licensed under a Creative Commons Attribution 4.0 International License, which permits use, sharing, adaptation, distribution and reproduction in any medium or format, as long as you give appropriate credit to the original author(s) and the source, provide a link to the Creative Commons licence, and indicate if changes were made. The images or other third party material in this article are included in the article's Creative Commons licence, unless indicated otherwise in a credit line to the material. If material is not included in the article's Creative Commons licence and your intended use is not permitted by statutory regulation or exceeds the permitted use, you will need to obtain permission directly from the copyright holder. To view a copy of this licence, visit http://creativecommons.org/licenses/by/4.0/.

\section{References}

Abdelkareem MA, El Haj Assad M, Sayed ET, Soudan B (2018) Recent progress in the use of renewable energy sources to power water desalination plants. Desalination 435:97-113

Abutayeh M, Li C, Goswami DY, Stefanakos EK (2014) Solar desalination. In: Kucera J (ed) Desalination. Scrivener Publishing LLC, Beverly, pp 551-582 
Ali MT, Fath HES, Armstrong PR (2011) A comprehensive technoeconomical review of indirect solar desalination. Renew Sustain Energy Rev 15(8):4187-4199

Al-Kharabsheh S, Goswami YD (2003) Analysis of an innovative water desalination system using low-grade solar heat. Desalination 156(1-3):323-332

Alkhudhiri A, Darwish N, Hilal N (2012) Membrane distillation: a comprehensive review. Desalination 287:2-18

Alnaimat F, Klausner J, Mathew B (2018) Solar desalination. In: Eyvaz M, Yüksel E (eds) Desalination and water treatment. Intech publications, London, pp 127-150

ASIRC (Australian Sustainable Industry Research Centre Ltd.) (2005) Overview of treatment processes for the production of fit for purpose water: desalination and membrane technologies report no.: R05-2207, 25 July

Awerbuch L, van der Mast V (2016) Geothermal Desalination potential for clean and affordable new water solutions. IDA International Energy and Environment Forum Creative Solutions and Innovative Strategies for Today's Water Challenges, pp 1-9

Awerbuch L, Lindemuth TE, May SC, Rogers AN (1976) Geothermal energy recovery process. Desalination 19(1):325-336

Baccioli A, Antonelli M, Desideri U, Grossi A (2018) Thermodynamic and economic analysis of the integration of Organic Rankine Cycle and Multi-Effect Distillationin waste-heat recovery applications. Energy 161:456-469. https://doi.org/10.1016/J.ENERG Y.2018.07.150

Boegli WJ, Suemoto SH, Trompeter KM (1977) Geothermal desalting at the East Mesa test site. Desalination 22(1-3):77-90

Bouchekima B (2003) A small solar desalination plant for the production of drinking water in remote arid areas of southern Algeria. Desalination 159(2):197-204. https://doi.org/10.1016/s0011 $-9164(03) 90071-3$

Bourouni K, Martin R, Tadrist L (1999a) Analysis of heat transfer and evaporation in geothermal desalination units. Desalination 122(2-3):301-313

Bourouni K, Deronzier JC, Tadrist L (1999b) Experimentation and modelling of an innovative geothermal desalination unit. Desalination 125(1999): 147

Calise F, d'Accadia MD, Macaluso A, Piacentino A, Vanoli L (2016) Exergetic and exergoeconomic analysis of a novel hybrid solargeothermal polygeneration system producing energy and water. Energy Convers Manag 115:200-220

Chandrasekharam D, Lashin A, Arifi NA, Al-Bassam AM, Chandrasekhar V (2019) Geothermal energy for sustainable water resources management. Int J Green Energy. https://doi. org/10.1080/15435075.2019.1685998

Curcio E, Drioli E (2005) Membrane distillation and related operations: a review. Sep Purif Rev 34(1):35-86

Davies PA, Orfi J (2014) Self-powered desalination of geothermal saline groundwater: technical feasibility. Water 6:3409-3432. https://doi.org/10.3390/w6113409

Drouiche N, Ghaffour N, Naceur MW, Mahmoudi H, Ouslimane T (2011) Reasons for the fast growing seawater desalination capacity in Algeria. Water Resour Manag 25(11):2743-2754

El-Dessouky HT, Ettouney HM, Al-Juwayhel F (2000) Multiple effect evaporation: vapour compression desalination processes. Chem Eng Res Des 78(4):662-676

Eltawil MA, Zhengming Z, Yuan L (2008) Renewable energy powered desalination systems: technologies and economics-state of the art. In: Twelfth international water technology conference, IWTC12, pp 1-38

Ettouney HM, El-Dessouky HT, Alatiqi I (1999) Chemical engineering progress, $\mathrm{p} 43$

Fernandez-Gonzalez C, Dominguez-Ramos A, Ibañez R, Irabien A (2015) Sustainability assessment of electrodialysis powered by photovoltaic solar energy for freshwater production. Renew Sustain Energy Rev 47:604-615

Fernhndez JL, Chargoy N (1990) Multi-stage indirectly heated solar still. Sol Energy 44(4):215

García-Rodríguez L (2002) Seawater desalination driven by renewable energies: a review. Desalination 143(2):103-113

Garmana MA, Muntasserb MA (2008) Sizing and thermal study of salinity gradient solar ponds connecting with the MED desalination unit. Desalination 222(1-3):689-695

Ghaffour N, Missimer TM, Amy GL (2013) Technical review and evaluation of the economics of water desalination: current and future challenges for better water supply sustainability. Desalination 309:197-207

Ghaffour N, Lattemann S, Missimer T, Ng KC, Sinha S, Amy G (2014) Renewable energy-driven innovative energy-efficient desalination technologies. Appl Energy 136:1155-1165

Ghaffour N, Bundschuh J, Mahmoudi H, Goosen MFA (2015) Renewable energy-driven desalination technologies: a comprehensive review on challenges and potential applications of integrated systems. Desalination 356:94-114

Goosen M, Mahmoudi H, Ghaffour N, Sablani SS (2011) Application of renewable energies for water desalination. https://doi. org/10.5772/14011

Gude VG (2016) Geothermal source potential for water desalination: current status and future perspective. Renew Sustain Energy Rev 57:1038-1065. https://doi.org/10.1016/j.rser.2015.12.186

Gude VG (2019) Geothermal desalination. Desalin Water Water. https ://doi.org/10.1002/9781119407874.ch15

Kabeel AE, Hamed MH, Omara ZM, Sharshir SW (2013) Water desalination using a humidification-dehumidification technique: a detailed review. Nat Resour 2013(4):286-305

Karytsas (1996) Mediterranean conference on renewable energy sources for water production, European Commission, EURORED Network, CRES, Santorini, Greece, 1996, pp 128-131

Koroneos C, Roumbas G (2012) Geothermal waters heat integration for the desalination of sea water. Desalin Water Treat 37(1-3):69-76

Krishna HJ (2004) Introduction to desalination technologies. Texas Water Dev 2:1-7

Liponi A, Wieland C, Bacciolia A (2020) Multi-effect distillation plants for small-scale seawater desalination: thermodynamic and economic improvement. Energy Convers Manag 205:1-14

Lu H, Walton JC, Swift AHP (2000) International Desalination and Water Reuse, IO (3):35-43

Lund JW, Freeston DH, Boyd TL (2011) Direct utilization of geothermal energy 2010 worldwide review. Geothermics 40(3):159-180

Luqman M, Bicer Y, Al-Ansari T (2019) Thermodynamic analysis of an oxy-hydrogen combustor supported solar and wind energybased sustainable polygeneration system for remote locations. Int J Hydrog Energy. https://doi.org/10.1016/j.ijhydene.2018.12.191

Mahmoudi H, Spahis N, Goosen MFA, Sablani S, Abdul-Wahab S, Ghaffour N, Drouiche N (2009a) Assessment of wind energy to power solar brackish water greenhouse desalination units: a case study from Algeria. J Renew Sustain Energy Rev. https://doi. org/10.1016/j.rser.2009.03.001

Mahmoudi H, Ouagued A, Ghaffour N (2009b) Capacity building strategies and policy for desalination using renewable energies in Algeria. J Renew Sustain Energy Rev 13:921-926

Mahmoudi H, Spahis N, Goosen MFA, Ghaffour N, Drouiche N, Ouagued A (2010) Application of geothermal energy for heating and fresh water production in a brackish water greenhouse desalination unit: a case study from Algeria. J Renew Sustain Energy Rev 14(1):512-517

Micale G, Cipollina A, Rizzuti L (2009) Seawater desalination for freshwater production. Seawater Desalin. https://doi. org/10.1007/978-3-642-01150-4_1 
Müller-Holst H, Engelhardt M, Schölkopf W (1999) Small-scale thermal seawater desalination simulation and optimization of system design. Desalination 122:255-262

Narayan GP, Sharqawy MH, Summers EK, Lienhard JH, Zubair SM, Antar MA (2010) The potential of solar-driven humidificationdehumidification desalination for small-scale decentralized water production. Renew Sustain Energy Rev 14(4):1187-1201

Qiblawey HM, Banat F (2008) Solar thermal desalination technologies. Desalination 220(1-3):633-644. https://doi.org/10.1016/j. desal.2007.01.059

Salem MG (2013) Solar desalination as an adaptation tool for climate change impacts on the water resources of Egypt, pp 1-94

Schwarzer K, Vieira ME, Faber C, Müller C (2001) Solar thermal desalination system with heat recovery. Desalination 137(1-3):23-29

Shah M, Sircar A, Shaikh N, Patel K, Thakar V, Sharma D, Sarkar P, Vaidya D (2018a) Groundwater analysis of Dholera geothermal field, Gujarat, India for suitable applications. Groundw for Sustain Dev 7:143-156

Shah M, Vaidya D, Sircar A (2018b) Using Monte Carlo simulation to estimate geo-thermal resource in Dholera geothermal field, Gujarat, India. Multiscale Multidiscip Model Exp Des. https:// doi.org/10.1007/s41939-018-0008-x

Shah M, Kathiriya H, Kakadiya M, Boghara V, Sircar A, Thakore S (2018c) Model design of condenser for solar assisted geothermal cooling system using software simulation. Model Earth Syst Environ. https://doi.org/10.1007/s40808-018-0516-z

Shah M, Sircar A, Shaikh N, Patel K, Sharma S, Vaidya D (2019a) Comprehensive geochemical/hydrochemical and geo-thermometry analysis of Unai geothermal field, Gujarat, India. Acta Geochim 38:145. https://doi.org/10.1007/s11631-018-0291-6

Shah M, Sircar A, Varsada R, Vaishnani S, Savaliya U, Faldu M, Vaidya D, Bhattacharya P (2019b) Assessment of geothermal water quality for industrial and irrigation purposes in the Unai geothermal field, Gujarat, India. Groundw Sustain Dev 8:59-68
Shah B, Kansara B, Shankar J, Soni M, Bhimjiyani P, Bhanushali T, Shah M, Sircar A (2019c) Reckoning of water quality for irrigation and drinking purposes in the konkan geothermal provinces, Maharashtra, India. Groundw Sustain Dev. https://doi. org/10.1016/j.gsd.2019.100247

Shah N, Vyas D, Shah K et al (2019d) Solar-assisted geothermal heat pump models for space heating and cooling. Int J Energy Water Res 3:329-341. https://doi.org/10.1007/s42108-019-00040-w

Shatat M, Riffat SB (2014) Water desalination technologies utilizing conventional and renewable energy sources. Int J Low Carbon Technol 9(1):1-19. https://doi.org/10.1093/ijlct/cts025

Sircar A, Shah M, Sahajpal S, Vaidya D, Dhale S, Choudhary A (2015) Geothermal exploration in Gujarat: case study from Dholera, India. Geotherm Energy 3:1-22

Suárez-Arriaga M-C, Bundschuh J, Samaniego F (2014) Assessment of submarine geothermal resources and development of tools to quantify their energy potentials for environmentally sustainable development. J Clean Prod 83:21-32

Tanaka K, Yamashita A, Watanabe K (1981) Experimental and analytical study of the tilted wick-type solar still. In: Proceedings of the ISES congress, Solar World Forum, Brighton, England, vol 2, pp 1087-1091

Tivey MK (2013) Modeling chimney growth and associated fluid flow at seafloor hydrothermal vent sites. Geophys Monogr Ser 91:158-177

Ullah I, Rasul M (2018) Recent developments in solar thermal desalination technologies: a review. Energies 12(1):119

Ward J (2003) A plastic solar water purifier with high output. Sol Energy 75(5):433-437

Yu G, Yu Z (2019) Combined power and freshwater generation driven by liquid-dominated geothermal sources. Energies 12:1562

Publisher's Note Springer Nature remains neutral with regard to jurisdictional claims in published maps and institutional affiliations. 